\title{
Effect of the Production Conditions of Continuously Cast Steels on the Degree of Hot Rolled Product Downgrading
}

\author{
Krisztián WIZNER, ${ }^{1}$ Attila KŐVÁRI ${ }^{2}$ \\ ${ }^{1}$ ISD Dunaferr Zrt., Dunaújváros, Hungary,wizner.krisztian@isd-dunaferr.hu \\ ${ }^{2}$ University of Dunaújváros, Institute of Engineering, Dunaújváros, Hungary, kovari@uniduna.hu
}

\begin{abstract}
Nowadays, quality development is a growing challenge, which places a heavy burden on economic operators, especially on smaller companies. ISD Dunaferr Zrt is the largest steel company in Hungary with its annual steel production of about 2 million tons, but it is small on a global scale. Taking advantage of the opportunities, locating the hidden problems, qualitative development and productivity enhancement can be realized without major investment. This study points out the steel production and casting parameters that have the greatest impact on the quality of the hot rolled product (sheet and coil) and touches upon the effect of rolled product final thickness on the ratio of downgrading. As a result the examination of overheating shows correlation with the ratio of downgrading, but the age of the mould does not. Regarding the thickness of the rolled product, it can be stated that in the case of thicker products (above $9 \mathrm{~mm}$ ) the ratio of downgrading increases.
\end{abstract}

Keywords: steel, slab, coil, casting, quality.

\section{Introduction}

In September 2018, Dunaferr Zrt's continuous casting machine no. 1 was completely reconstructed, the most significant step of which was the replacement and modernization of mould level control automatics.

Downgrading ratio of the hot rolled products made from slabs cast before and after the reconstruction showed a clear improvement.

Further analyzing the data generated after the reconstruction (16,697 coils of 3,928 heats), we examined the relationship between various, primarily steel production and casting parameters and the hot rolled product downgrading data.

ISD Dunaferr Zrt's Steelworks has two LD converters (each with the capacity of 135 tons) and two vertically arranged continuous steel casters (2-2 strands). The raw steel is treated by a threestand ladle metallurgy station located between the converters and the casting machines, without the possibility of heating. The converters are supplied with hot metal by two blast furnaces, with the total capacity of $\sim 4000 \mathrm{~m}^{3}$.
After the oxygen blowing (in BOF), the liquid steel gradually cools down, until it solidifies in the casting machine. Without the possibility of heating, the treatments from BOF to mould are limited. The degree of cooling depends on multiple circumstances, for example the quality, type and quantity of alloying materials, the quantity of the flushing inert gas, but mainly on the thermal state of the ladle.

\section{BOF, Ladle treatment station}

In the liquid state of steel it is important to reduce the inclusion content. This can be achieved by removing active oxygen to intensify the diffusion process (afterflushing in BOF), using a deoxidizing reagent of appropriate quality and quantity (aluminium) and removing as much formed inclusion as possible with inert gas rinsing.

After the oxygen blowing, the oxygen content of the steel can reach 800-1000 ppm.

The following technical variables were analyzed during the study:

- Amount of afterflushed inert gas (argon) in the BOF; 
- Amount of aluminum added for deoxidation broken down by type (solid "mokka", loose "shredder") [1];

- The amount of Al wire used to set the final aluminum content at the ladle treatment station;

- The amount of inert gas (argon) used to flush the steel in the ladle, broken down by source:

- from the bottom of the ladle through porous plug, different intensity (lower argon);

- from the top, through lance, to approx. $2 \mathrm{~m}$ below the surface, with high intensity (upper argon).

Rolled product properties inherited from the liquid phase depend primarily on homogeneity, inclusion content and morphology, and chemical composition. These variables are reflected mainly in the mechanical properties (e.g. tensile strength, elongation). If the mechanical properties do not meet the quality requirements, the product would usually be reclassified and would not be downgraded. For this reason, the data of the BOF and ladle treatment station did not show any correlation with downgrading data.

The product would be downgraded due to the inclusion content in the liquid steel only if the amount/morphology of inclusions in the sample takenin thevicinity of theinterventionjustifiesit, or when it appears on the surface of the rolled product and thereby the mechanical surface analysis system (Cognex) or if the human eye can detect it.

\section{Continuous casting machine}

The casting processes, mainly that of the mould processes, play the greatest role in the formation of internal and external structure of cast slabs. [24]. Examination of the data shows that the material is downgraded typically due to surface cracking and scaling. The formation of these errors is

Table 1. Ratio of the causes of downgrading

\begin{tabular}{|l|l|}
\hline \multicolumn{1}{|c|}{ Cause of downgrading } & Ratio \\
\hline Torn edge & $0.00 \%$ \\
\hline Scale on the edge & $0.20 \%$ \\
\hline Cracked on the edge & $0.05 \%$ \\
\hline Scale on the surface & $1.18 \%$ \\
\hline Rupture on surface & $0.11 \%$ \\
\hline Inclusion on the surface & $0.27 \%$ \\
\hline Cracked on the surface & $0.14 \%$ \\
\hline Based on an inclusion test & $0.18 \%$ \\
\hline Total downgrading & $\mathbf{2 . 1 1} \%$ \\
\hline
\end{tabular}

primarily the result of complex processes in the mould [5-7].

\subsection{Tundish}

The primary role of the tundish is to create a liquid steel buffer, which is essential for continuous casting during the ladle change. The temperature probe in the tundish provides data on the temperature of the steel entering the mould. The difference between the liquidus temperature calculated from the steel composition and the actual measured temperature gives the degree of overheating of the liquid steel. Low overheating poses technical risk, because cast steel may solidify before needed and there is no possibility of heat transmission outside the BOF. High overheating means casting safety, but a greater burden on the cooling system (mould, secondary cooling zones).

The Al-O balance shifting during the cooling of steel triggers a fine inclusion precipitation, the higher the degree of cooling, the more significant inclusion precipitation is. In the mould, this phenomenon intensifies as a result of intense, direct heat dissipation, and inclusions can more easily get close to the surface.

Figure 1 shows the relationship between downgrading and the overheat in the tundish.

\subsection{Mould}

The mould makes an oscillating motion [8-10] to form a solid shell on liquid steel, which is capable of retaining the internal liquid portion against the ferrostatic pressure during its movement to-

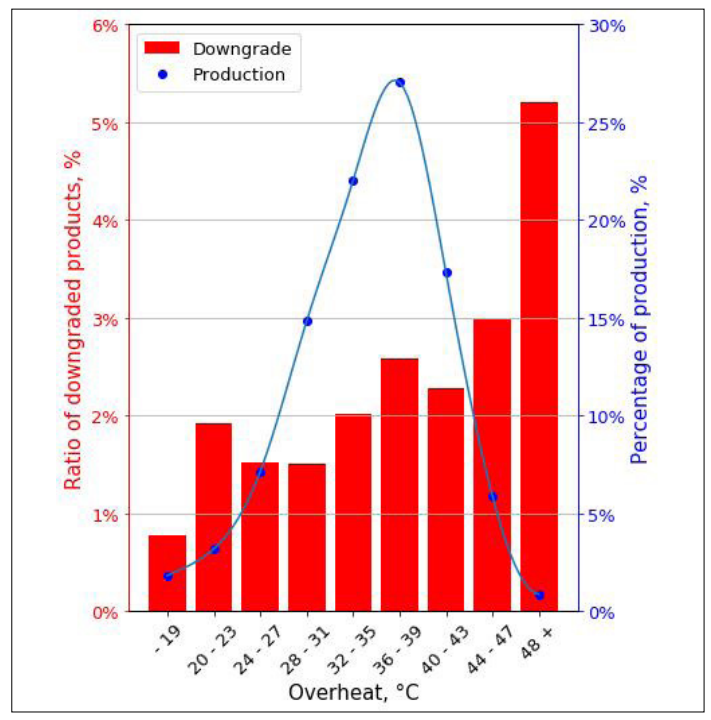

Figure 1. Relationship between the ratio of downgrading and the degree of overheating. 
wards the lower zones. In the mould, heat is removed through water-cooled, nickel-plated copper sheets.

\subsubsection{The age of the mould}

The mould is subject to numerous mechanical effects during casting, which can cause uneven wear and tear on the inner surface of the mould, and these internal irregularities may affect the surface quality of cast slabs. Due to the feeding of the dummy bar from below before casting, mechanical wear occurs at the bottom of the cooling plates. In the case of splashes of liquid steel, the steel droplets may fall into the surface of the cooling plates, which are removed by grinding in cold state. At the meniscus of the held steel level, traces of liquid steel and melting casting powder can be observed.

Contrary to the assumption, the values in Figure 2 do not show a significant correlation between the degree of downgrading and the age of the mould. Presumably because the solid and liquid steel directly touches the wall of the mould only on the short section, such a deep roughness cannot develop in this section, the depth of which would exceed the thickness of the layer burning down later in the reheating furnace.

\subsubsection{Fluctuation of casting speed and steel level in the mould}

The change in casting speed and the mould steel surface have a significant effect on both the inter-

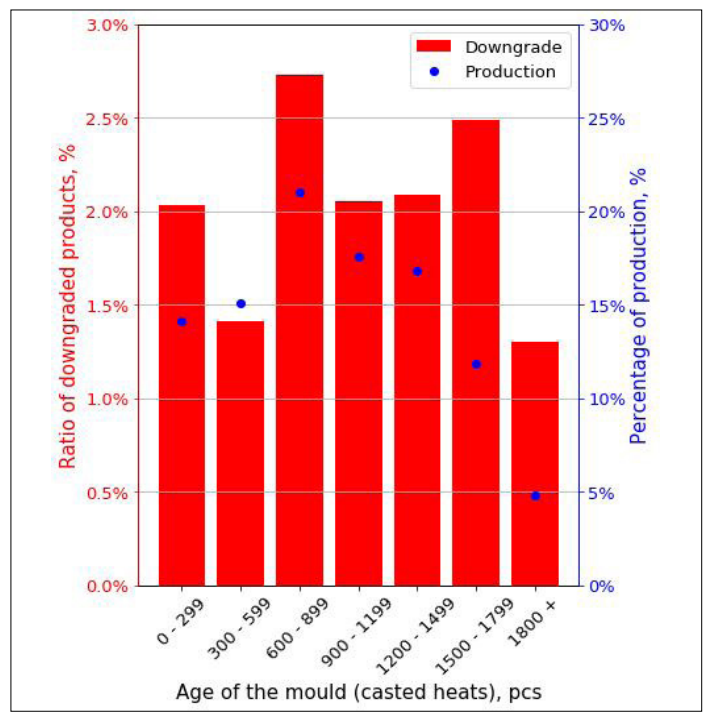

Figure 2. Relationship between downgrading and the age of the mould. nal and external properties of cast strand. [11-15] Examining these changes in terms of time and length did not produce significant results, which is presumably due to the fact that the strand sections burdened with major changes are cut off and subsequently not used. Thus they do not cause significant downgrading.

\subsection{Secondary cooling zone}

The role of the secondary cooling zones below the mould is the stable support of the strand and its further cooling until it solidifies in entire cross section. Earlier observations suggested that casting problems (e.g. bearing breakage, roller bumps) occur quickly and visibly. They did not appear during the period under investigation, so their effects were not investigated.

The cooling strategy of the strand is determined first of all by the quality of the heat and the width of the strand (section size). The degree of overheating has an effect on the maximum casting speed of the strand, so that the appropriate heat dissipation can be achieved in order to solidify the entire cross section. [15]

Due to chemical similarity, only the section size affects the cooling strategy of the examined steel grades, therefore it has been investigated on this basis.

In Figure 3 the data show an extremely high ratio of downgrading at the widest section width.

The amount cast on B15 (1550 mm wide) section and the high ratio of downgraded material sub-

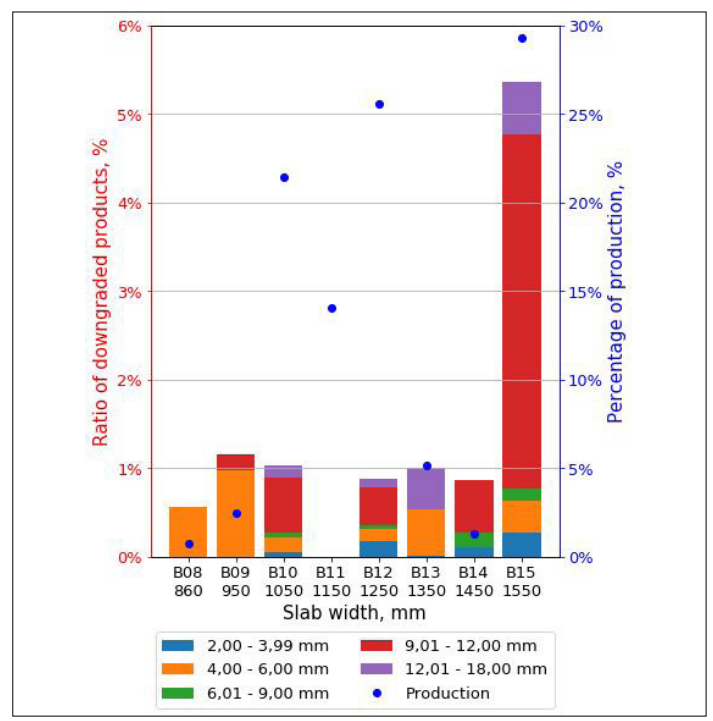

Figure 3. Relationship between the ratio of downgrading to slab width. 
ject to regular inspections during the investigated period exclude that the problem arises from local nozzle failure, clogging. Rather, it suggests that production parameters, which depend on the section size in the production line (Casting Machine, Hot Rolling Mill), is responsible for the phenomenon. Finding the exact reasons is beyond the scope of this study.

\section{Hot rolling}

In this study it is mainly the technological variables of steelworks that were analyzed. Hot rolling mill production properties were not subject to the study, but based on experience it seemed appropriate to examine the relationship between the thickness of the rolled product (degree of deformation) and the downgrading. The thickness categories were selected according to the manufacturing technology of typical products.

According to conjecture, it can also be seen from the chart in Figure 4 that the degree of downgrading in thicker product categories is significantly higher.

\section{Conclusions}

The tested properties of the BOF and ladle treatment station mainly affect the mechanical properties of the hot rolled product. In case of non-compliance, the product is usually reclassified to a different quality. Presumably for this reason, investigations did not reveal any correlation with downgrading.

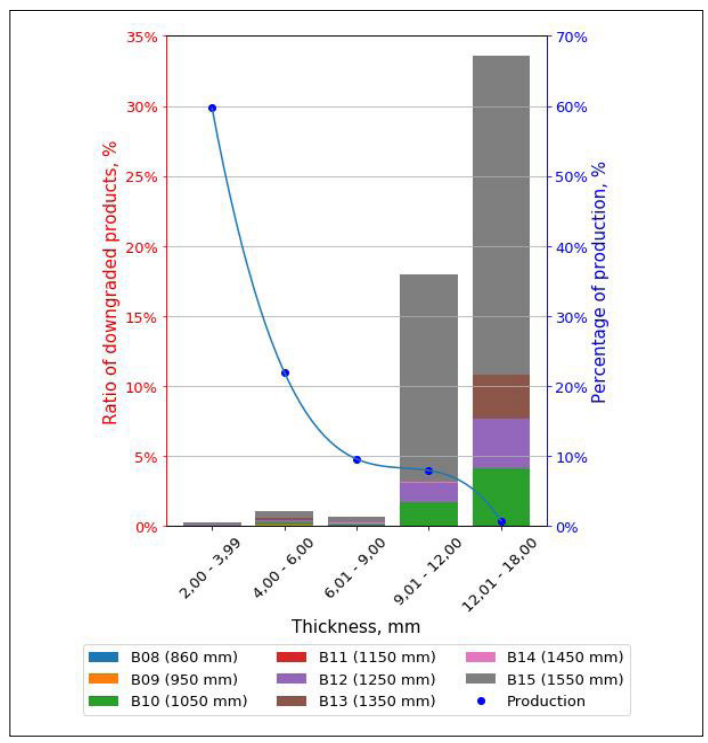

Figure 4. Relationship between downgrading and the final thickness of rolled flat product.
The examination of overheating shows correlation with downgrading. In the lower temperature range (near the liquidus temperature), the steel solidification process can already start due to cooling in the casting chain. However, in the higher temperature range, the thermal burden of the mould increases, which will have a negative effect on the surface of the strand. Current casting with high overheating, mostly at $35-40{ }^{\circ} \mathrm{C}$, is the consequence of the supply of raw materials and refractory materials from non-permanent suppliers. Due to the uncertainty, it is necessary to keep a constant supply of safety heat reserve. Supplying raw materials and refractory materials from continuous, steady sources can reduce tapping and casting temperatures, leading to quality improvements and cost savings.

There was no correlation between the age of the mould and downgrading. This is presumably due to the short, direct contact of the molten steel with the mould wall, during which no such deep defect arising from the uneven surface of the mould can form that will not burn down in the reheating furnace.

Investigating the change in casting speed and mould steel level did not deliver any measurable results. This is primarily due to the fact that the strand segments affected by major changes are cut out and not rolled.

According to the data, the downgrading ratio of $1550 \mathrm{~mm}$ wide (B15) slabs, which is significantly higher than the others, is not a maintenance problem (e.g. nozzle clogging), instead it is caused by other cooling specifics depending on the section size. Exploring the cause of the error affects complex review of the cooling strategy of both the continuous caster and the hot rolling mill.

Regarding the thickness of the rolled product, it is clear regardless of the section size, that in the case of thicker products (above $9 \mathrm{~mm}$ ) the degree of downgrading increases significantly. This leap in the case of products thicker than $12 \mathrm{~mm}$ can be partly explained by the fact that they can be sold only in coils. There is no possibility of cutting and thus a full coil is downgraded even in the case of partial problems. Figure 3. and 4. show that the largest portion of the thick product (above $9 \mathrm{~mm}$ ) is produced on a B15 (1550 mm wide) section.

Based on the above data, it can be concluded that the effects of the section size and the thickness of the rolled product add up, and the risk of downgrading significantly increases in case of thick, wide products. 


\section{Acknowledgments}

The study is funded by „EFOP-3.6.1-16-2016-00003

$\mathrm{K}+\mathrm{F}+\mathrm{I}$ folyamatok hosszú távú megerősítése a Dunaújvárosi Egyetemen” project.

\section{References}

[1] Wizner K., Kővári A.: Efficiency of different kinds of aluminiums during deoxidation in the Steelworks of ISD Dunaferr Co. Ltd. IOP Conf. Series: Materials Science and Engineering, 426. (2018) 012052 https://doi.org/10.1088/1757-899X/426/1/012052

[2] Meng Y., Thomas B. G.: Heat transfer and solidification model of continuous slab casting: CON1D. Metall. \& Material Trans., 34B/5. (2003) 685-705. https://doi.org/10.1007/s11663-003-0040-y

[3] Zhang L., Pluschkell W., Thomas B. G.: Nucleation and growth of alumina inclusion during steel deoxidation. In: Proceeding of $85^{\text {th }}$ Steelmaking Conference, Vol. 85. ISS, Warrendale, PA, 2002. 463-476.

[4] Thomas B. G., Jenkins M., Mahapatra R. B.: Investigation of strand surface defects using mold instrumentation and modeling. Ironmaking \& Steelmaking, 31/6. (2004) 485-494.

https://doi.org/10.1179/030192304225019261

[5] Brimacombe J. K., Sorimachi K.: Crack formation in the continuous casting of steel. Metallurgical Transactions, B, 8/2. (1977) 489-505. https://doi.org/10.1007/BF02696937

[6] Schmidt K.-D. et al.: Consequent improvement of surface quality by systematic analysis of slabs. Steel Research, 74/11. (2003) 659-666.

[7] Thomas B. G.: Modeling of continuous casting defects related to mold fluid flow. In: Proceeding of $3^{\text {rd }}$ Int. Congress on Science \& Technology of Steelmaking, AIST, Warrendale, PA, 2005. 847-861.

[8] Shin H.-J., Lee G. G., Choi W. Y., Kang S. M., Park J. H., Kim S. H., Thomas B.G.: Effect of mold oscilla- tion on powder consumption and hook formation in ultra low carbon steel slabs. Iron Steel Technology, 2/9. (2004) 15-17.

[9] Thomas B. G., Sengupta J., Ojeda C.: Mechanism of hook and oscillation mark formation in ultra-low carbon steel. In: Proceeding of Second Baosteel Biennial Conference, Vol. 1, 2006. 112-117.

[10] Sengupta J., Thomas B. G., Shin H.-J., Lee G. G., Kim S.-H.: A new mechanism of hook formation during continuous casting of ultra-low-carbon steel slabs. Metallurgical and Materials Transactions, 37/5. (2006) 1597-1611. https://doi.org/10.1007/s11661-006-0103-1

[11] Thomas B. G.: Continuous Casting of Steel. In: Modelling for casting and solidification process, (Ed: O. Yu) Marcel Dekker, New York, NY, 2001. 499-540.

[12] Sengupta J.: Effect of a sudden level fluctuation on hook formation during continuous casting of ultralow carbon steel slabs. In: Modeling of Casting, Welding, and Advanced Solidification Processes XI. (Szerk. Gandin C. A., Allison J. E.). TMS, Warrendale, PA, 2006. 727-736.

[13] Shin H-J., Thomas B. G., Lee G. G., Park J. M., Lee C. H., Kim S. H.: Analysis of hook formation mechanism in ultralow-carbon steel using CON1D heat flow solidification model. Materials Science and Technology 2, TMS, Warrendale, PA, Vol. II, 2004. 11-26.

[14] Zhang Q., Wang L., Wang X.: Influence of casting speed variation during unsteady continuous casting on non-metallic inclusions in IF steel slabs. ISIJ International, 46/10. (2006) 1421-1426.

[15] Wang Y., Zhang L.: Transient fluid flow phenomena during continuous casting: Part II-cast speed change, temperature fluctuation, and steel grade mixing. ISIJ International, 50/12. (2010) 17831791.

https://doi.org/10.2355/isijinternational.50.1783 